\title{
Climate change and violent conflict in Europe over the last millennium
}

\author{
Richard S. J. Tol • Sebastian Wagner
}

Received: 24 January 2008 / Accepted: 26 July 2009 / Published online: 30 September 2009

(C) Springer Science + Business Media B.V. 2009

\begin{abstract}
We investigate the relationship between a thousand-year history of violent conflict in Europe and various reconstructions of temperature and precipitation. We find that conflict was more intense during colder period, just like Zhang et al. (Clim Change 76:459-477, 2006) found for China. This relationship weakens in the industrialized era, and is not robust to the details of the climate reconstruction or to the sample period. As the correlation is negative and weakening, it appears that global warming would not lead to an increase in violent conflict in temperature climates.
\end{abstract}

\section{Introduction}

In the gloomier scenarios of climate change, violent conflict plays a key part. War would break out over declining water resources, and millions of refugees would cause mayhem. The Nobel Peace Prize of 2007 was partly awarded to the IPCC and $\mathrm{Al}$ Gore for their contribution to slowing climate change and thus preventing war. Scenarios of climate-change-induced violence can be painted with abandon (e.g., Schwartz and Randall 2003), because there is in fact very little research to either support or refute such claims. The broader literature on violent conflict and

R. S. J. Tol (凶)

Economic and Social Research Institute, Dublin, Ireland

e-mail: richard.tol@esri.ie

R. S. J. Tol

Institute for Environmental Studies, Vrije Universiteit, Amsterdam, The Netherlands

R. S. J. Tol

Department of Spatial Economics, Vrije Universiteit, Amsterdam, The Netherlands

S. Wagner

Institute for Coastal Research, GKSS Research Centre, Geesthacht, Germany 
environmental scarcity suggests that climate change would at most be a contributing factor to violent conflict, but no attempts have been made to quantify these insights and apply it to climate change. Zhang et al. (2006) broke new ground. They construct a dataset of climate and violent conflict for China for the last millennium, and show that the Chinese are more inclined to fight each other when it is cold. They link this to reduced agricultural productivity. Here, we replicate their research for Europe, for which similar data are available.

Research into the determinants of violent conflict has concluded that resource scarcity is at best a contributing factor to, but never a cause of war (Alesina and Spolaore 2005; Collier and Hoeffler 1998, 2005; Homer-Dixon 1991, 1994; HomerDixon et al. 1993; Maxwell and Reuveny 2000; Nordås and Gleditsch 2007). The corollary is that climate-change-induced resource scarcity would not lead to war either, although it may intensify pre-existing conflicts.

Clearly, an intensification of conflict would be something to worry about. Butkiewicz and Yanikkaya (2005) find that political instability (i.e., the chance of war) reduces per capita economic growth in the poorest countries by $2 \%$ per yearalthough actual war has no significant effect in their model. Conflict may thus be a big factor in the economic impacts of climate change (cf. Tol et al. 2000), but, as said, it is not clear whether climate change would lead to conflict. Barnett (2006) argues that conflict directly increases vulnerability - conflict also indirectly increases vulnerability through its adverse impact on development (Yohe and Tol 2002).

Despite the conclusions of studies quoted above, it is possible to imagine a scenario in which climate change does cause violent conflict. One example may be prolonged drought, perhaps in the Horn of Africa (Held et al. 2006), followed by mass migration. The impact on conflict is speculative. Firstly, migration is the result from a complex of push and pull factors, not from a single push factor (McGregor 1994; McLeman and Smit 2006). Secondly, drought is only a real problem for the poor; a scenario like this would happen only if warming and drying outpace development. If not, food imports (Reilly and Schimmelpfennig 1999) or desalination (Zhou and Tol 2005) may be the preferred options. Thirdly, drought is a slow-onset disaster. It may exhaust people before they move. Poor and exhausted people are unlikely to take up arms, and if they do, they are probably not very effective. The human suffering would be substantial nonetheless.

A potentially more serious example is rapid sea level rise in the major deltas of Asia and Africa. Coastal plains are often fertile and hence densely populated (Nicholls and Small 2002). Without coastal protection, inundation, erosion and saltwater intrusion would drive many people to higher grounds (Nicholls and Tol 2006). They may resettle peacefully, or start quarrelling with their new neighbours. One can speculate about the consequences of large-scale migrations today. In West Africa, for instance, the situation is already so tense that additional refugees are unlikely to do any good-note that the coasts of Cameroon, Gabon and Nigeria are particularly vulnerable to sea level rise. Similarly, forced migration of large numbers of Bengali from the coastal plain to the hills of northern Indian and Bangladesh would not be without problems either, and may even escalate to nuclear war. However, these impacts will not be on today's world. Sixty-six years ago, Western Europe was at war. In 2075, South Asia and West Africa may be stable and prosperous. 
Most of the research on climate change and violent conflict is qualitative in nature (Atwell 2001; Barnett and Adger 2007; Buhaug et al. 2008; Raleigh and Urdal 2007; Reuveny 2007; WBGU 2007). The study by Zhang et al. (2006) is the only one to look quantitatively at the relationship between climate change and violent conflict. ${ }^{1}$ They conclude that conflict was more prevalent during cold periods of Chinese history, and speculate that food scarcity is the reason. In this study we use a similar approach as in the study of Zhang et al. (2006) for Europe.

In the analyses below, we relate an index of violent conflict to indices of temperature and precipitation. We find that in Europe as in China, cold weather coincides with violence. We do not believe that people fight to keep warm. Rather, temperature and precipitation are proxy variables for agricultural production. ${ }^{2}$ Like Zhang et al. (2006), we thus test the hypothesis that an extended period of bad harvests lead to violent conflict. Obviously, there are many other reasons for (civil) war; and few wars can be pinpointed to a single cause. However, as long as such "other reasons" are uncorrelated to climate, our estimates of the impact of climate variability on violent conflict are unbiased (albeit inefficient). We use Europe as a testbed for our hypothesis because of records of climatic variability and violent conflict are wellestablished for the last millennium. Extending our analysis further back in time is restricted by the availability of reliable climatic data before $1000 \mathrm{AD}$. Also climate model simulations are not yet carried out for earlier periods. Extending the analysis to other continents would not be possible because of a lack of data on warfare.

Our paper is structured as follows: Section 2 presents the data, followed by descriptive statistics in Section 3. Section 4 discusses the results of regression analysis. Section 5 contains some concluding remarks.

\section{Data}

Although the historical literature on violent conflict in Europe is large, surveys that cover extended periods and provided quantified data are scarce. Our source is http://www.warscholar.com $/ .^{3}$ This has data on the number of conflicts only. Wars typically last for longer than 1 year; we count a conflict in every year that it raged; the Eighty Years War, for example, is recorded as a conflict for each year between 1568 and 1648. The selection criterion is whether a conflict is significant enough to be noted by historians. This undoubtedly led to an under representation of earlier conflicts, particularly in areas without central authority. To the best of our knowledge, there are no data on the number of military involved in the conflict, the area affected, the intensity of the fighting, the human impact, or the economic

\footnotetext{
${ }^{1}$ Hendrix and Glaser (2007) and Meier et al. (2007) estimate relationships between weather and violent conflict.

${ }^{2}$ Although any agronomist would argue that things are more complicated

${ }^{3}$ The UCDP/PRIO Armed Conflict Dataset (www.prio.no/CSCW/Datasets/Armed-Conflict/ UCDP-PRIO/) and the COSIMO dataset (http://www.hiik.de/en/kosimo/index.html) start in 1946 only. Peter Brecke's data (http://www.inta.gatech.edu/peter/PSS99_paper.html) extends back to 1400 .
} 


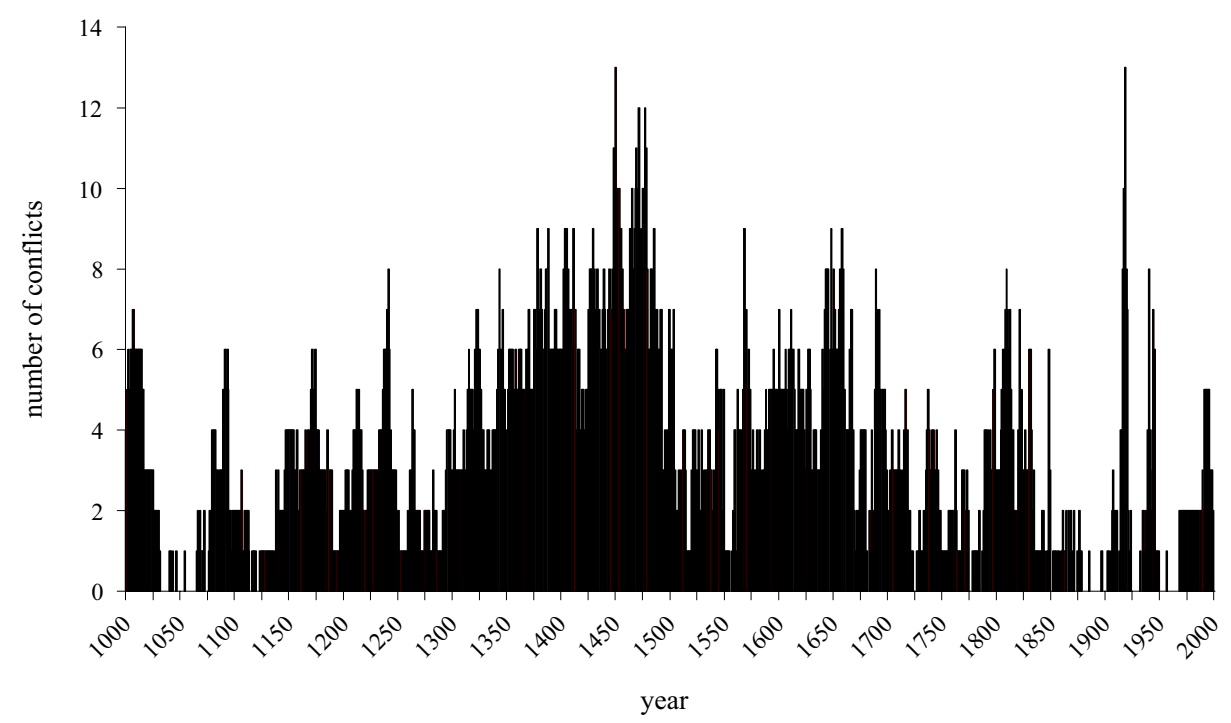

Fig. 1 Annual number of violent conflicts in Europe according to www.warscholar.com

impact. ${ }^{4}$ Note that large wars (e.g., the Thirty Years War, World War I and II) are registered as multiple conflicts, and that large battles (e.g., Azincourt, Verdun) are separately registered too. The indicator therefore captures the intensity as well as the frequency of conflict (Fig. 1).

The climatic data for 1500-1900 stem from the gridded datasets of Luterbacher et al. (2004) for temperature and Pauling et al. (2006) for precipitation; see also Xoplaki et al. (2005). These reconstructions are based on instrumental and proxybased records. The advantage using gridded data sets instead of raw station data relates to that fact that these data (i) include a huge number of meteorological observations and proxy data and (ii) the data are quality checked for inconsistencies and inhomogeneities. In this study we use annual mean values of European temperature and precipitation. For the period prior to 1500 different reconstructions of northern hemispheric temperatures of the last millennium have been used. Data have been downloaded from the NOAA paleoclimate web-page (http://www.ncdc.noaa.gov/paleo/recons.html).

Additionally, results from a model simulation with the coupled atmosphere-ocean model ECHO-G, forced with reconstructions of solar and volcanic activity and greenhouse gas concentrations (GHG) have been used for this analysis (von Storch et al. 2004).

\section{Descriptive statistics}

In the following we present a correlation analysis between selected climatic data fields and warfare in Europe. An important point that is also addressed is on the

\footnotetext{
${ }^{4}$ Note that Sorokin (1937) presents data on the size of the army and war casualties, but only for selected countries and only averaged over centuries.
} 
statistical significance of the correlations. Results are given for both, spatially resolved patterns for Europe and averaged for Europe and the Northern Hemisphere. Additional to results based on observational and proxy studies also information from the output of climate model simulations will be analysed.

Figure 2 shows the (Pearson) correlation maps between violent conflicts (in the whole of Europe) and temperature and precipitation (in a specific grid cell), respectively. The right panels are based on unfiltered climatic data. In the left panels data have been smoothed with a 10 years Hamming window. According to Fig. 2,

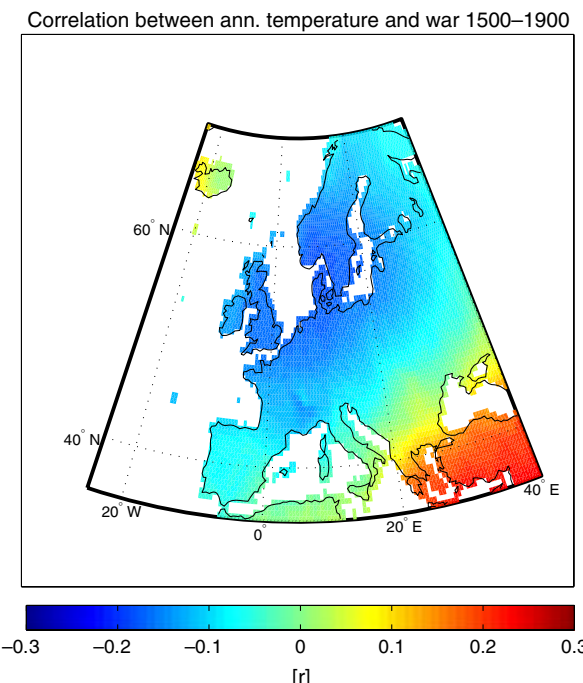

[r]

Correlation between ann. temperature and war 1500-1900 HW10

Correlation between ann. precipitation and war 1500-1900

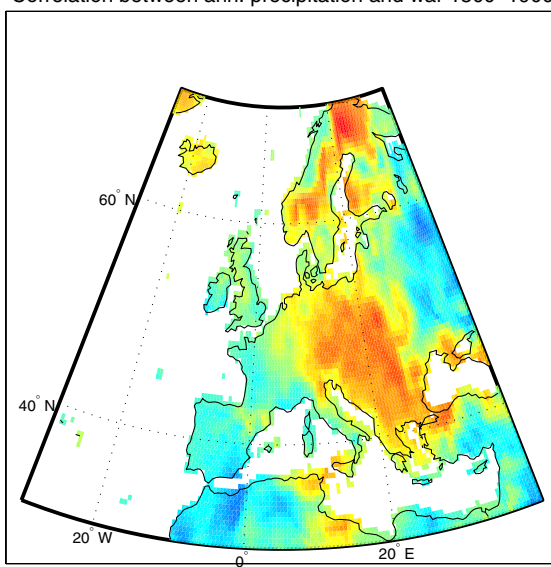

Correlation between ann. precipitation and war 1500-1900 HW10

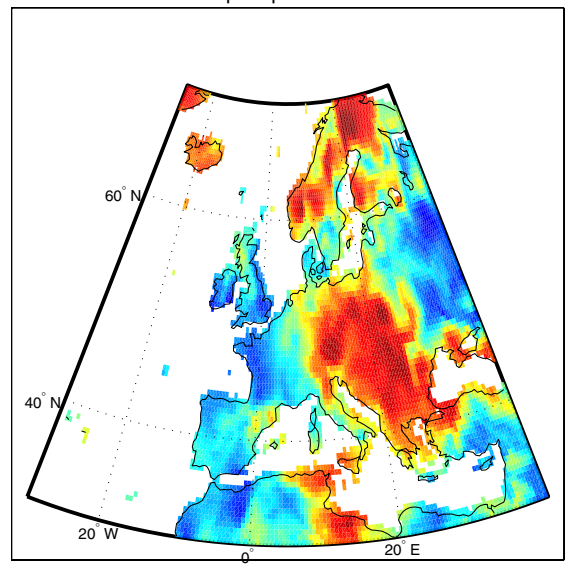

$-0.4$

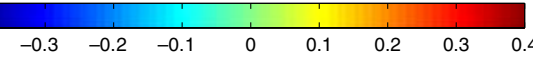

$[r]$
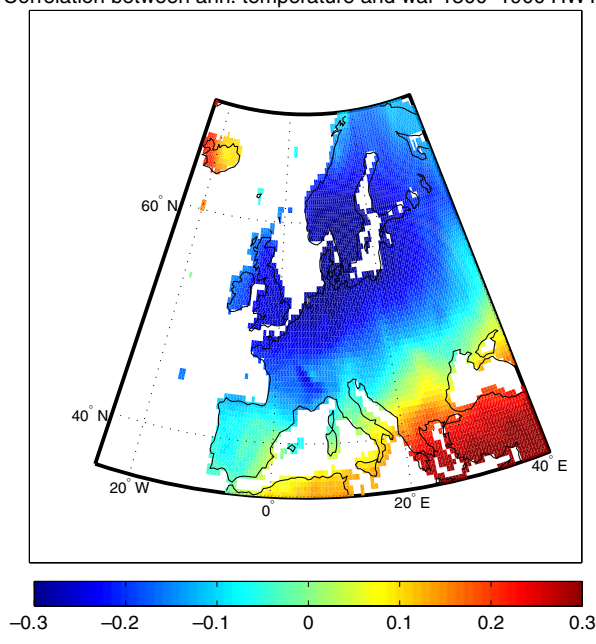

[r]

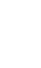


temperatures are negatively correlated with war conflicts over central and northern Europe. The homogeneous negative correlations over large areas indicate the largescale characteristics of temperature. The temperature pattern might also reflect changes in atmospheric circulation patterns, such as the North Atlantic Oscillation (Hurrell and Van Loon 1997). In contrast to negative correlations over mainland Europe, positive correlations are evident over the Balkans. These correlations should however not be overinterpreted, because the Balkans are largely excluded from the violent conflict data base. From a dynamical point of view these correlations might be an artifact caused by large-scale atmospheric teleconnection patterns. The basic pattern is similar for data filtered with a 10 year Hamming window, whereas the higher correlations are possibly due to filtering-out of the inter-annual climate variability.

For precipitation, correlations are positive in a band from Scandinavia over midEurope to the Balkans, which may point to bad harvests due to waterlogging, while the correlation is negative further East, which may point to bad harvests due to drought. The pattern is spatially more inhomogeneous than the one for temperature, emphasizing the local to regional-scale character of precipitation. For the prefiltered data the pattern is also similar, albeit with higher correlations. The higher correlations might be again caused by the smoothing of the annual precipitation data.

Standard tests for the significance of correlations assume that the samples are independent. However, this assumption is violated for the war data, because data show serial autocorrelations in the order of $r_{1}=0.81 ;\left(r_{1}\right.$ is the autocorrelation coefficient with 1 year lag). Also, the annual temperature data show weak serial autocorrelations. To estimate more robustly the effect of the serial autocorrelations on the levels of statistical significance of the correlations, the region $10^{\circ} \mathrm{W}-30^{\circ} \mathrm{E}$ and $40^{\circ} \mathrm{N}-60^{\circ} \mathrm{N}$ has been selected and its average temperature and precipitation considered (cf. Fig. 2). The region was selected because it better represents mainland Europe, where most violent conflicts took place (cf. also http://www. warscholar.com/).

Different filters and lags have been applied on the data. Results for temperatures are listed in Table 1; for temperature and precipitation in Tables 1 and 2. The statistical significance of the correlations has been estimated by Monte-Carlo simulations. Here, the original (Gaussian) white-noise time series have been transformed to first-order autoregressive processes according to the estimated values of the lag-1 autocorrelation of observed temperature and precipitation, respectively. (The serial autocorrelation of temperature is $r_{1}=0.15$, for precipitation $r_{1}=0$.) One thousand synthetic time series have been correlated with the war time series and the lower

Table 1 Pearson correlation coefficients between war and temperature (according to Luterbacher et al. 2004)

\begin{tabular}{lllrr}
\hline Filter/lag & 0 & 5 & 10 & \multicolumn{1}{c}{15} \\
\hline 0 & $-0.14(-0.11)$ & -0.10 & 0.00 & 0.00 \\
5 & $-0.22(-0.19)$ & -0.18 & 0.00 & 0.00 \\
10 & $-0.24(-0.26)$ & -0.25 & 0.00 & 0.00 \\
20 & $-0.27(-0.36)$ & -0.29 & -0.18 & -0.11 \\
\hline
\end{tabular}

Time-series have been detrended prior to the analysis. For the time-series, a Hamming window has been applied. In parentheses threshold values of the $2.5 \%$ level of significance (two-tailed) are given 
Table 2 Pearson correlation between European war data and temperature (according to Luterbacher et al. 2004) and precipitation (according to Pauling et al. 2006) for the periods 15001700 and $1701-1900$

\begin{tabular}{lllll}
\hline & Temperature & & Precipitation & \\
\hline Period & $1500-1700$ & $1701-1900$ & $1500-1700$ & $1701-1900$ \\
Filter & & & & \\
0 & $-0.30(-0.15)$ & 0 & $+0.16(0.06)$ & 0 \\
5 & $-0.39(-0.26)$ & 0 & $+0.23(0.25)$ & 0 \\
10 & $-0.43(-0.37)$ & 0 & $+0.24(0.37)$ & 0 \\
20 & $-0.42(-0.52)$ & 0 & $+0.19(0.52)$ & 0 \\
\hline
\end{tabular}

Time series have been de-trended prior to analysis. For the filtered time series a Hamming window has been applied. In parentheses threshold values of the $2.5 \%$ level of significance (two-tailed) are given

$2.5 \%$ and upper $97.5 \%$ confidence levels have been derived from the resulting correlations.

Results for precipitation show correlations even lower than for temperature. This might be related to the fact that regions with temperature correlations of the same sign (cf. Fig. 3) are different than regions with the same sign of precipitation correlation. The averaging leads to the mixture of regions showing correlations with different signs. Therefore correlations of the area-averaged fields are lower than the spatially resolved.

Figure 4 shows that the correlations are stronger in the more distant past. This confirms the agricultural hypothesis. Agriculture became progressively less important over the period, because of economic development, and agriculture became less dependent on the weather, because of improved cultivation methods and better fertilizers.

The upper part of Table 3 shows correlations between European war data and temperatures of the Northern Hemisphere based on different reconstructions extending back to year 1000. Results are given for the whole period 1000-1990 and for the pre-industrial era 1000-1750. The temperature according to Mann and Jones (2003) correlates best with the number of violent conflicts, and the data of d'Arrigo

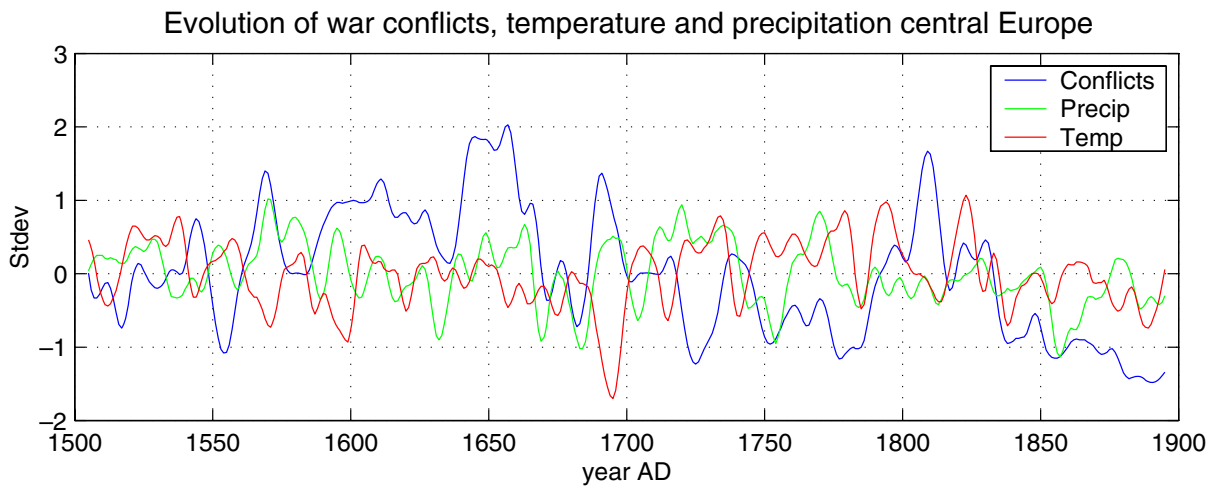

Fig. 3 Standardized time series of war conflicts, temperature and precipitation for Central Europe. Time series have been filtered with a 10 year Gaussian filter 

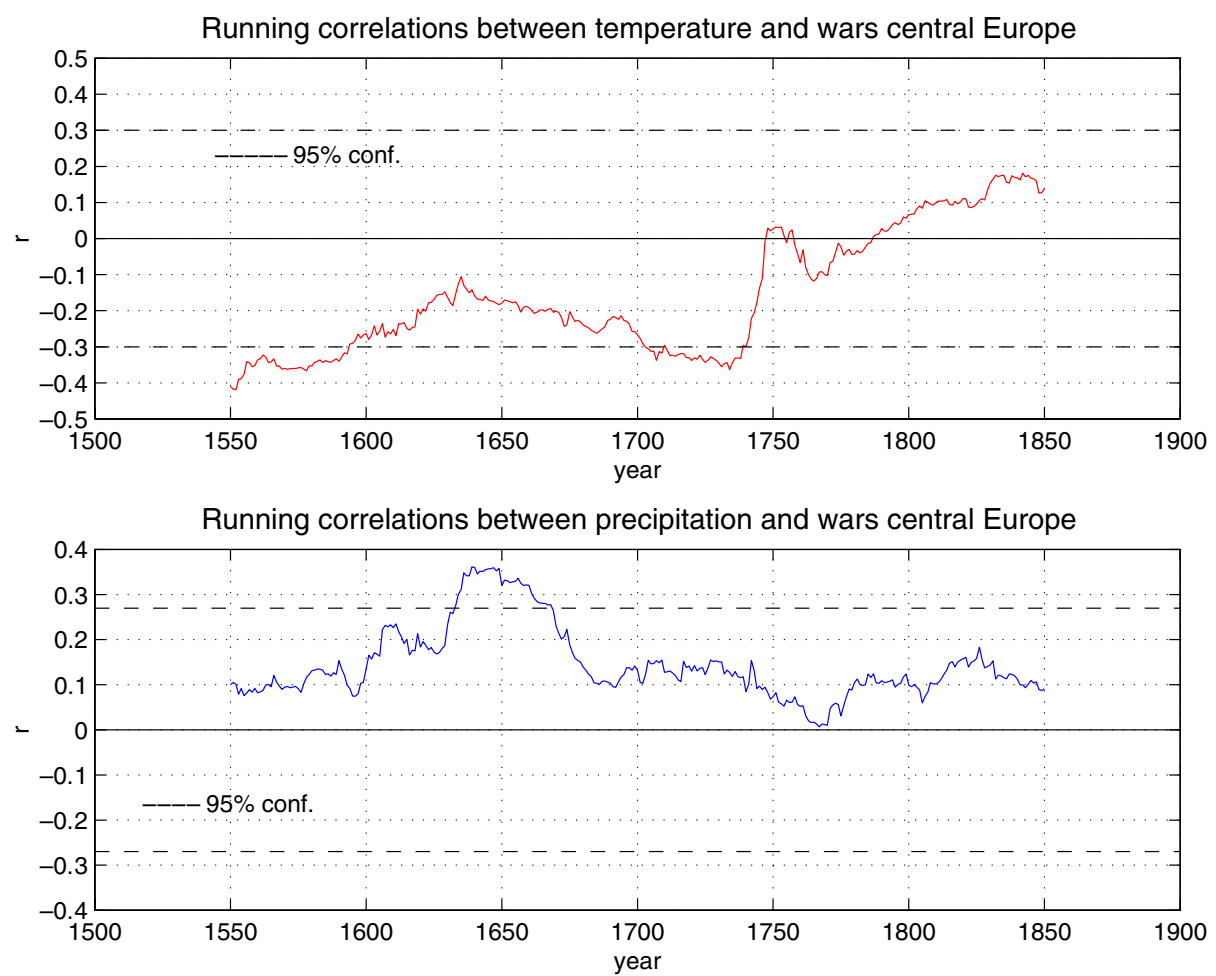

Fig. 4 Running correlations with a 50 year window between climate time series (temperature: top panel; precipitation: bottom panel) in central Europe and wars. The dashed lines indicate the $95 \%$ confidence intervals based on 1000 Monte Carlo simulations

et al. (2006) shows weakest correlation. Differences between the two periods are not as clear-cut as for the European temperatures. For some reconstructions correlations are even lower in the early period (Esper et al. 2002; Moberg et al. 2005).

Table 3 Pearson correlation between European war data for different temperature reconstructions of the Northern Hemisphere

\begin{tabular}{lcc}
\hline & $1000-1990$ & $1000-1750$ \\
\hline Crowley and Lowery 2000 & $-0.19(-0.21)$ & -0.24 \\
Esper et al. 2002 & $-0.21(-0.15)$ & -0.11 \\
Mann and Jones 2003 & $-0.33(-0.36)$ & -0.33 \\
D'Arrigo et al. 2006 $^{\prime}$ & $-0.14(-0.12)$ & -0.15 \\
Moberg et al. 2005 $^{\text {Zorita et al. 2003, Northern Hemisphere }}{ }^{\mathrm{a}}$ & $-0.23(-0.21)$ & -0.18 \\
Zorita et al. 2003, Europe $^{\mathrm{a}}$ & $-0.31(-0.21)$ & -0.32 \\
Control Northern Hemisphere $^{\mathrm{a}}$ & $-0.18(-0.10)$ & -0.14 \\
Control Europe $^{\mathrm{a}}$ & 0 & 0 \\
\hline
\end{tabular}

Time series have been de-trended prior to analysis. In parentheses threshold values of the $2.5 \%$ level of significance (two-tailed) are given based on 1000 Monte Carlo simulations

a Temperature from a climate model simulation forced with reconstructions of solar and volcanic activity and greenhouse gas concentrations 
The strength of correlations does however considerably differ among the different simulations, which can most likely be attributed to the different amount of serial autocorrelations of the different reconstructions. This is also supported by the change in the significance threshold related to the $2.5 \%$ significance level. The latter is highest for reconstructions showing highest correlations. Thus it can be concluded that the basic correlation between $\mathrm{NH}$ temperature and European wars is slightly negative and that the strength of the correlation is strongly influenced by the serial autocorrelations of the reconstruction under consideration.

The lower part of Table 3 shows correlations between wars and simulated temperatures with a global GCM. Here changes of solar and volcanic activity and GHG concentrations have been used to force the model in the period 1000-1990 (Erik). To test the plausibility of results also correlations between a simulation with the same climate model and war with constant external forcing has been calculated (Control) (Zorita et al. 2003).

Correlations between the simulated temperatures and European wars also show negative correlations, consistent with results obtained for reconstructions based on observational data and proxy data. For the control simulation correlations are zero. Therefore one might hypothesize that also changes in external forcings, such as solar and volcanic activity, partly influenced the warfare in the last millennium.

The correlation analysis thus confirms the finding of Zhang et al. (2006): In the temperature zone, lower temperatures are accompanied with violent conflict, and potentially also may cause it. The effect may have grown weaker as Europe developed. At the same time, the conclusion is not particularly convincing as the correlations is neither strong nor robust.

In the next section, we use regression analysis to look into the same issue. The main advantages of regression analysis over correlation analysis are that multiple influences are studied at once, and that it is easier to incorporate the dynamics of the series under study. We test the impact of temperature on violent conflict against a number of agnostic models that capture any other cause of war, and a single structural variable (the Reformation).

\section{Regression analysis}

Table 4 shows the results from a number of regression models. In the first model, the number of violent conflicts is regressed on the temperature (according to Mann and Jones 2003). The estimated effect is strong-nine conflicts per degree coolingand highly significant. This model does not pass any diagnostic checks, however. Particularly, the errors are autocorrelated. The second model adds as explanatory variables the numbers of conflicts in the previous 2 years. These are highly significant, because conflicts tend to last longer than a few years. Lags between 3 and 10 years are not significant (results not shown). With this correction for autocorrelation, the temperature effect is estimated to be much weaker-one conflict per degree cooling - and it is significant at the 5\% level but not at the $1 \%$ level. Recall that there are almost 1,000 observations.

Many things have changed in Europe in the last 1,000 years, and one would expect that the relationship between temperature and violent conflict has changed too. Therefore, we included interaction terms between temperature on the one hand 
Table 4 Regression results: the number of conflicts in Europe (war) is regressed on a time trend (time), temperature, and conflict levels in previous years

\begin{tabular}{|c|c|c|c|c|c|c|}
\hline & & Base & AR & Time-variant & Reformation & Time trend \\
\hline$\overline{\text { Constant }}$ & $10^{0}$ & $1.10(0.24)$ & $0.10(42)$ & $0.31(0.14)$ & $0.55(40)$ & -4.79 \\
\hline Time & $10^{-3}$ & & & & & $7.05 * *(2.19)$ \\
\hline Time $^{2}$ & $10^{-6}$ & & & & & $2.25 * * *(11)$ \\
\hline Temperature & $10^{0}$ & $-8.62 * * *(0.83)$ & $-0.99 * *(0.42)$ & $18.53 * *(6.19)$ & $24.36 * * *(6.75)$ & $-0.38(0.54)$ \\
\hline Temp*time & $10^{-1}$ & & & $-0.27 * * *(0.08)$ & $-0.32 * * *(0.09)$ & \\
\hline Temp*time ${ }^{2}$ & $10^{-6}$ & & & $9.37 * * *(2.70)$ & $1.05^{* * *}(0.27)$ & \\
\hline Luther & & & & & $-0.34 * *(0.16)$ & $-0.31 *(0.16)$ \\
\hline $\operatorname{War}(t-1)$ & $10^{0}$ & & $0.76 * * *(0.03)$ & $0.75 * * *(0.03)$ & $0.74 * * *(0.03)$ & $0.75 * * *(0.03)$ \\
\hline War $(t-2)$ & $10^{0}$ & & $0.13 * * *(0.03)$ & $0.11 * *(0.03)$ & $0.11 * *(0.03)$ & $0.11 * *(0.03)$ \\
\hline$R_{\mathrm{adj}}^{2}$ & & 0.10 & 0.79 & 0.80 & 0.80 & 0.80 \\
\hline $\mathrm{LL}$ & & $-2,241.47$ & $-1,512.89$ & $-1,505.67$ & $-1,503.36$ & $-1,504.81$ \\
\hline
\end{tabular}

Standard deviations are given in brackets

*coefficients that are significant at the $10 \%$ level

** coefficients that are significant at the $5 \%$ level

*** coefficients that are significant at the $1 \%$ level

and year and year-squared on the other hand. All three terms are highly significant (cf. Table 4). Note that the linear term is significant only if the quadratic term is included as well (results not shown). The combined effect of the three temperature terms is shown in Fig. 5. It is significant at the 5\% level between 1300 and 1650 only. This period roughly coincides with the period of maximum conflict. This suggests that climate was a contributing factor to the outbreak of conflict in an already tense situation, rather than a root cause. Including a trend break in 1517 (the start of the Reformation) does not affect the overall pattern, although the period of a significant effect of temperature on conflict is delayed to 1400-1725 (cf. Fig. 5). The Reformation dummy is negative (cf. Table 4).

Table 4 also includes a model with a quadratic trend that is not interacted with temperature. The temperature effect is no longer significant. However, this model describes the data less well than the model with time interactions. Furthermore, if both trend and interaction terms are included, then the latter are more significant.

Table 5 shows the estimated effect of temperature on violent conflict for various subsamples. The period 1300-1725 is the initial sample, and this is extended in steps of 50 years. A model with two lags and no interaction terms is used. The effect of temperature is insignificant for the subsamples. The temperature is significant only if almost the entire sample is used to estimate the model.

Table 6 repeats this analysis, but now with subsamples starting at either end of the total sample. Table 6 confirms Table 5. The significance of the temperature effect is due to the gradient in temperature between either end of the sample and the middle. Short-term variations in temperature have no significant effect on violent conflict, but the long-term variations do. This may be because worsening climate conditions contribute to a gradual build-up of tension.

Table 7 shows the results for the seven alternative temperature reconstructions. Only four are significant at the 5\% level. The Mann temperature correlates best with the war record.

The regression analysis confirms the correlation analysis. One can make the case that violent conflict was more frequent and intense during cold periods. However, this case is weaker for some temperature reconstructions than for others. Further- 

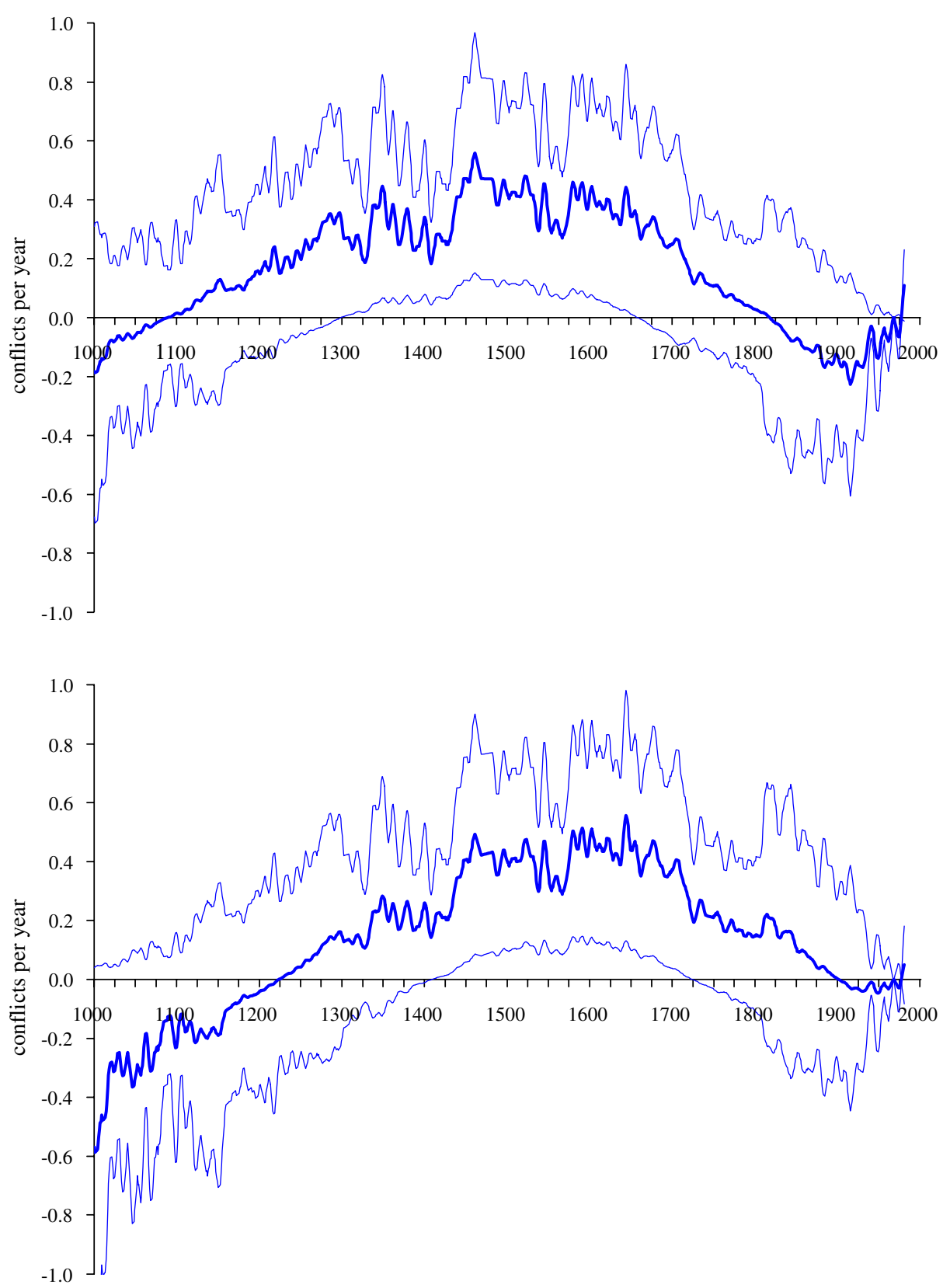

Fig. 5 Predicted number of wars due to temperature (according to Mann) without a Reformation dummy (top panel) and with a Reformation dummy (bottom panel). The thick line is the expected value, the thin lines its $95 \%$ confidence interval

more, the main signal is in the secular trends, rather than decadal and annual variations. Europe gradually cooled and then warmed over the millennium, while conflict worsened and then waned. 
Table 5 Estimated effect of the temperature on the number of conflicts in Europe, using the AR2 model of Table 4, for different subsamples

Standard deviations are given in brackets

* coefficients that are significant at the $10 \%$ level ** coefficients that are significant at the $5 \%$ level

\begin{tabular}{ll}
\hline Sample & Mean (St.dev.) \\
\hline $1300-1725$ & $-0.43(0.83)$ \\
$1275-1750$ & $-0.59(0.78)$ \\
$1250-1775$ & $-0.90 *(0.74)$ \\
$1225-1800$ & $-0.87 *(0.69)$ \\
$1200-1825$ & $-0.57(0.67)$ \\
$1175-1850$ & $-0.60(0.63)$ \\
$1150-1875$ & $-0.49(0.60)$ \\
$1125-1900$ & $-0.58(0.59)$ \\
$1100-1925$ & $-1.02 *(0.57)$ \\
$1075-1950$ & $-0.87 *(0.51)$ \\
$1050-1975$ & $-0.94 *(0.45)$ \\
$1002-1980$ & $-0.99 *(0.42)$ \\
\hline
\end{tabular}

Table 6 Estimated effect of the temperature on the number of conflicts in Europe, using the AR2 model of Table 4, for different subsamples

Standard deviations are given in brackets

* coefficients that are significant at the $10 \%$ level

** coefficients that are significant at the $5 \%$ level

\begin{tabular}{ll}
\hline Sample & Mean (St.dev.) \\
\hline $1002-1200$ & $-1.22 *(1.08)$ \\
$1002-1300$ & $-0.35(0.71)$ \\
$1002-1400$ & $-0.86 *(0.67)$ \\
$1002-1500$ & $-1.38 * *(0.65)$ \\
$1002-1600$ & $-1.21 *(0.59)$ \\
$1002-1700$ & $-1.14 * *(0.52)$ \\
$1002-1800$ & $-1.22 * *(0.50)$ \\
$1002-1900$ & $-0.87 *(0.48)$ \\
$1002-1980$ & $-0.99 * *(0.42)$ \\
$1800-1980$ & $-0.39(0.83)$ \\
$1700-1980$ & $-0.61(0.70)$ \\
$1600-1980$ & $-1.57 * *(0.63)$ \\
$1500-1980$ & $-1.68 * *(0.61)$ \\
$1400-1980$ & $-1.16 *(0.58)$ \\
$1300-1980$ & $-0.97 *(0.53)$ \\
$1200-1980$ & $-0.84 *(0.49)$ \\
$1100-1980$ & $-0.94 * *(0.43)$ \\
$1002-1980$ & $-0.99 * *(0.42)$ \\
\hline
\end{tabular}

Table 7 Estimated effect of the temperature on the number of conflicts in Europe, using the AR2 model of Table 4, for different temperature reconstructions

\begin{tabular}{ll}
\hline Temperature & Mean (St.dev.) \\
\hline Crowley & $-0.93^{* *}(0.40)$ \\
D'Arrigo & $-0.20^{*}(0.18)$ \\
Erik-Europe & $-0.08^{*}(0.05)$ \\
Erik-Northern Hemisphere & $-0.32^{* *}(0.12)$ \\
Esper & $-0.46^{*}(0.30)$ \\
Mann & $-0.99 * *(0.42)$ \\
Moberg & $-0.35^{* *}(0.17)$ \\
\hline
\end{tabular}

Standard deviations are given in brackets

*coefficients that are significant at the $10 \%$ level

** coefficients that are significant at the $5 \%$ level 


\section{Discussion and conclusion}

In this paper, we study the relationship between climate change and violent conflict over the past millennium in Europe. Our results do not show a clear-cut picture: We present some evidence that periods with lower temperatures in the pre-industrial era are accompanied by violent conflicts, as do Zhang et al. (2006). However, we also show that this evidence is not particularly robust. If one has strong priors that climate change causes conflict, our results provide confirmation. However, if one has strong priors that there is no link, our results do not overthrow such doubt. If anything, lower temperatures imply violence, and this effect is much weaker in the modern world than it was in pre-industrial times. This implies that future global warming is not likely to lead to (civil) war between (within) European countries. Should anyone ever seriously have believed that, this paper does put that idea to rest-unless of course one argues that the waning significance of the effect of climate on conflict in recent centuries has nothing to do with the changed economic, political and social circumstances in Europe but rather is a prelude to sign change after which heat will imply conflict, that is, that a pattern of the last millennium will be reversed in the next century.

We also showed the importance in estimating the proper level of statistical significance. The data series for both climate and war, show serial autocorrelations, affecting the threshold values for the statistical significance at a given level. This can lead-despite the high correlations in terms of absolute values-to false conclusions on the real strength of the correlations.

More research will have to be done. Conflict may be due to lower than average temperatures in the temperate climates of China (Zhang et al. 2006) and Europe (this paper). It does not follow that a warmer future would be more peaceful because the relationship between temperature and warfare may be reversed in the tropicsbut this has yet to be quantified. Data availability and quality may be an issueexcept perhaps for the Indian subcontinent. A finer statistical analysis would be worthwhile too. We consider the ultimate cause (climate change) and final effect (violent conflict), but one could include more parts of the causal chain (e.g., climate change, agricultural production, economic deprivation, violent conflict). All this is deferred to future research.

Acknowledgements Joshua Howe, Hans von Storch, Eduardo Zorita and two anonymous referees had useful comments on an earlier version.

\section{References}

Alesina A, Spolaore E (2005) The size of nations. MIT, Cambridge

Atwell WS (2001) Volcanism and short-term climatic change in East Asian and World history, c. 1200-1699. J World Hist 12(1):29-98

Barnett J (2006) Climate change, insecurity and injustice. In: Adger WN, Paavola J, Huq S, Mace MJ (eds) Fairness in adaptation to climate change. MIT, Cambridge, pp 115-130

Barnett J, Adger WN (2007) Climate change, human security and violent conflict. Polit Geogr 26(6):639-655

Buhaug H, Gleditsch NP, Theisen OM (2008) Implications of climate change for armed conflict. Social dimensions of climate change working paper, World Bank, Washington, DC 
Butkiewicz JL, Yanikkaya H (2005) The impact of sociopolitical instability on economic growth: analysis and implications. J Policy Model 27(5):629-645

Collier P, Hoeffler A (1998) On economic causes of civil war. Oxf Econ Pap 50:563-573

Collier P, Hoeffler A (2005) Resource rents, governance and conflicts. J Confl Resolut 49(4):625-633

Crowley TJ, Lowery TS (2000) Northern hemisphere temperature reconstruction. Ambio 29:51-54

d'Arrigo R, Wilson R, Jacoby G (2006) On the long-term context for late twentieth century warming. J Geophys Res 111. doi:10.1029/2005JD006352

Esper J, Cook ER, Schweingruber FH (2002) Low-frequency signals in long tree-ring chronologies for reconstructing past temperature variability. Science 295:2250-2253

Held IM, Delworth TL, Lu J, Findell KL, Knutson TR (2006) Simulation of Sahel drought in the 20th and 21st centuries. Proc Natl Acad Sci USA 103(4):1152-1153

Hendrix CS, Glaser SM (2007) Trends and triggers: climate, climate change and civil conflict in SubSaharan Africa. Polit Geogr 26(6):695-715

Homer-Dixon TF (1991) On the threshold-environmental changes as causes of acute conflict. Int Secur 16(2):76-116

Homer-Dixon TF (1994) Environmental scarcities and violent conflict: evidence from cases. Int Secur 19(1):5-40

Homer-Dixon TF, Boutwell JH, Rathjens GW (1993) Environmental change and violent conflict. Sci Am 268(2):38-45

Hurrell JW, Van Loon H (1997) Decadal variations in climate associated with the North Atlantic Oscillation. Clim Change 36:301-326

Luterbacher J, Dietrich D, Xoplaki E, Grosjean M, Wanner H (2004) European seasonal and annual temperature variability, trends, and extremes since 1500. Science 303:1499-1503. doi:10.1126/science.1093877

Mann ME, Jones PD (2003) Global surface temperatures over the past two millennia. Geophys Res Lett 30. doi:10.1029/2003GL017814

Maxwell JW, Reuveny R (2000) Resource scarcity and conflict in developing countries. J Peace Res 37(3):301-322

McGregor J (1994) Climate change and forced migration-implications for food security. Food Policy 19(2):120-132

McLeman R, Smit B (2006) Migration as an adaptation to climate change. Clim Change 76:31-53

Meier P, Bond D, Bond J (2007) Environmental influences on pastoral conflict in the Horn of Africa. Polit Geogr 26(6):716-735

Moberg A, Sonechkin DM, Holmgren K, Datsenko NM, Karlén W (2005) Highly variable Northern Hemisphere temperatures reconstructed from low- and high-resolution proxy data. Nature 433:613-617

Nicholls RJ, Small C (2002) Improved estimates of coastal population and exposure to hazards released. Eos Trans Am Geophys Union 83(28):301-305

Nicholls RJ, Tol RSJ (2006) Impacts and responses to sea-level rise: a global analysis of the SRES scenarios over the 21st century. Philos Trans R Soc Lond Ser A: Math Phys Eng Sci 361(1841): 1073-1095

Nordås R, Gleditsch NP (2007) Climate change and conflict. Polit Geogr 26(6):627-638

Pauling A, Luterbacher J, Casty C, Wanner H (2006) Five hundred years of gridded high-resolution precipitation reconstructions over Europe and the connection to large-scale circulation. Clim Dyn 26:387-405

Raleigh C, Urdal H (2007) Climate change, environmental degradation and armed conflict. Polit Geogr 26(6):674-694

Reilly JM, Schimmelpfennig D (1999) Agricultural impact assessment, vulnerability, and the scope for adaptation. Clim Change 43:745-788

Reuveny R (2007) Climate change-induced migration and violent conflict. Polit Geogr 26(6): $656-673$

Schwartz P, Randall D (2003) An abrupt climate change scenario and its implications for United States national security. Global Business Network, San Francisco

Sorokin PA (1937) Social and cultural dynamics. American Book, New York

Tol RSJ, Fankhauser S, Richels RG, Smith JB (2000) How much damage will climate change do? recent estimates. World Econ 1(4):179-206

von Storch H, Zorita E, Jones J, Dimitriev Y, González-Rouco F, Tett S (2004) Reconstructing past climate from noisy data. Science 306:679-682

WBGU (2007) World in transition: climate change as a security risk. German Advisory Council on Global Change, Berlin 
Xoplaki E, Luterbacher J, Paeth H, Dietrich D, Steiner N, Grosjean M, Wanner H (2005) European spring and autumn temperature variability and change of extremes over the last half millennium. Geophys Res Lett 32:L15713. doi:10.1029/2005GL023424

Yohe GW, Tol RSJ (2002) Indicators for social and economic coping capacity-moving towards a working definition of adaptive capacity. Glob Environ Change 12(1):25-40

Zhang DD, Jim CY, Lin GC-S, He Y-Q, Wang JJ, Lee HF (2006) Climatic change, wars and dynastic cycles in China over the last millennium. Clim Change 76:459-477

Zhou Y, Tol RSJ (2005) Evaluating the costs of desalination and water transport. Water Resour Res 41(3):W03003

Zorita E, González-Rouco F, Legutke S (2003) Testing the Mann et al (1998) approach to paleoclimate reconstructions in the context of a 1000-yr control simulation with the ECHO-G coupled climate model. J Climate 16:1378-1390 